\title{
Capillary Electrophoresis Single-Strand Conformational Polymorphisms as a Method to Differentiate Algal Species
}

\author{
Alice Jernigan and Christa Hestekin \\ Department of Chemical Engineering, University of Arkansas, Fayetteville, AR 72701, USA \\ Correspondence should be addressed to Christa Hestekin; chesteki@uark.edu
}

Received 20 November 2014; Revised 12 May 2015; Accepted 14 May 2015

Academic Editor: Chih-Ching Huang

Copyright ( 2015 A. Jernigan and C. Hestekin. This is an open access article distributed under the Creative Commons Attribution License, which permits unrestricted use, distribution, and reproduction in any medium, provided the original work is properly cited.

Capillary electrophoresis single-strand conformational polymorphism (CE-SSCP) was explored as a fast and inexpensive method to differentiate both prokaryotic (blue-green) and eukaryotic (green and brown) algae. A selection of two blue-green algae (Nostoc muscorum and Anabaena inaequalis), five green algae (Chlorella vulgaris, Oedogonium foveolatum, Mougeotia sp., Scenedesmus quadricauda, and Ulothrix fimbriata), and one brown algae (Ectocarpus sp.) were examined and CE-SSCP electropherogram "fingerprints" were compared to each other for two variable regions of either the 16S or 18S rDNA gene. The electropherogram patterns were remarkably stable and consistent for each particular species. The patterns were unique to each species, although some common features were observed between the different types of algae. CE-SSCP could be a useful method for monitoring changes in an algae species over time as potential shifts in species occurred.

\section{Introduction}

The two most frequently used traditional methods for taxonomic identification of algae beyond the genus level are by microscopic examination and genotyping [1-5]. Microscopic examination methods require skill and experience as they involve a thorough knowledge of the thousands of possible variations in the shape and morphology of the algae as well as familiarity with the algae ecology and reproduction [6]. To go beyond the genus level to species or substrains of a species can require a scanning electron microscope (SEM) or other more complicated tests and techniques such as in the case of diatoms [7]. Even at this level, there may still be some ambiguity and discussion among the experts in the field of phycology.

Genotyping, in which the DNA is extracted and sequenced, is another method. While giving excellent results, it requires skill and takes time and if hired out to a laboratory that specializes in sequencing, it can be costly. Genotyping requires primers that can isolate and amplify a portion of the genome of the species of interest, typically the $16 \mathrm{~S}$ rDNA gene [8-10] for prokaryotic algae (cyanobacteria or blue-green algae) and the $18 \mathrm{~S}$ rDNA gene [11] for eukaryotic algae. These genes are both highly conserved among algae but have regions of variability that can be used for species identification [2,11-13]. The sequence of these regions can then be compared to known sequences and the most likely species matching sequence can be determined.

While sequencing is the gold standard method for evaluation of sequence variants, alternative methods with more rapid analysis times and lower expense are also being evaluated for their potential. One such method is capillary electrophoresis single-strand conformational polymorphisms (CE-SSCP). SSCP entails heat denaturing the double stranded DNA until the hydrogen bonds holding the double helix backbone together disassociate and the DNA becomes two single strands in a dilute solution. These single strands of DNA are snap-cooled on ice causing the single strand to fold back on itself in ways that are dictated by its unique nucleotide sequence into something called a conformer. Under conditions of low temperature and nondenaturing polymer the single-stranded DNA conformers will migrate according to their shape and will have a distinct mobility. SSCP performed on a capillary electrophoresis instrument gives the advantages of automated loading of samples and the use of laser-induced fluorescence detection, which allows 
TABle 1: Pure cultures for fingerprint database.

\begin{tabular}{lcc}
\hline Genus and species & Class, type & Source/catalog number \\
\hline Chlorella vulgaris & Chlorophyceae, green algae & UTEX 395 \\
Ulothrix fimbriata & Chlorophyceae, green algae & UTEX LB 638 \\
Scenedesmus quadricauda & Chlorophyceae, green algae & UTEX B 614 \\
Oedogonium foveolatum & Chlorophyceae, green algae & UTEX LB 933 \\
Mougeotia sp. & Chlorophyceae, green algae & UTEX 758 \\
Ectocarpus sp. & Phaeophyceae, brown algae & UTEX LB 1433 \\
Anabaena inaequalis & Cyanophyceae, cyanobacterium & UTEX B 381 \\
Nostoc muscorum & Cyanophyceae, cyanobacterium & UTEX B 486 \\
\hline
\end{tabular}

TABLE 2: Primer information.

\begin{tabular}{lcccc}
\hline Primer name & Gene amplified & Variable region & Primer sequence & Fragment size* $^{*}$ \\
\hline V2F [14] & $16 \mathrm{~S}$ & V2 & GGCGAACGGGTGAGTAA & $239 \mathrm{bp}$ \\
V2R [14] & $16 \mathrm{~S}$ & $\mathrm{~V} 2$ & ACTGCTGCCTCCCGTAG & 239 bp \\
V3F [15] & $16 \mathrm{~S}$ & $\mathrm{~V} 3$ & CCAGACTCCTACGGGAGGCAG & $184 \mathrm{bp}$ \\
V3R [15] & $16 \mathrm{~S}$ & $\mathrm{~V} 3$ & CGTATTACCGCGGCTGCTG & $184 \mathrm{bp}$ \\
V7F & $18 \mathrm{~S}$ & $\mathrm{~V} 7$ & AACTTAAAGGAATTGACGGAA & $156 \mathrm{bp}$ \\
V7R & $18 \mathrm{~S}$ & $\mathrm{~V} 7$ & GCATCACAGACCTGTTATTGCCCC & $156 \mathrm{bp}$ \\
V9F & $18 \mathrm{~S}$ & $\mathrm{~V} 9$ & GTACACACCGCCCGTCGCACC & $310 \mathrm{bp}$ \\
V9R & $18 \mathrm{~S}$ & $\mathrm{~V} 9$ & TTCCGCAGGTTCACCTACGGA & $310 \mathrm{bp}$ \\
\hline
\end{tabular}

${ }^{*}$ Fragment size estimated from NCBI (http://www.ncbi.nlm.nih.gov).

for sensitive detection at low concentrations and repeatable results.

CE-SSCP has been used to successfully differentiate between mutated and nonmutated genes [9, 16-18] and also to identify and differentiate bacterial species from such diverse samples such as blood, cheese, and soil [14, 19-21]. In addition, Herrera-Supúlveda used CE-SSCP to monitor activities of harmful algal blooms of the Baja California Sur Coastal waters and noted significant advantages of this method over having to keep on hand an expert taxonomist [22]. In this research capillary electrophoresis single-strand conformational polymorphism (CE-SSCP) was explored to identify different algal species.

\section{Materials and Methods}

2.1. Pure Cultures. Six pure species level cultures and two genus level cultures were obtained from Carolina Biological Supply Company (Burlington, NC, USA). The eight different cultures represented three different types of algae including green algae, brown algae, and cyanobacteria. Table 1 gives a list of the various types of algal species used for the fingerprint database.

The live cultures were used for DNA extraction within a week of arrival. DNA was extracted using either the PowerPlant Pro DNA Isolation Kit from Mo Bio Laboratories (Carlsbad, CA, USA) or the DNeasy Plant Mini Kit from Qiagen (Germantown, MD, USA). The PowerPlant and the DNeasy Plant Mini Kit protocols were followed to obtain clean DNA samples for PCR.
2.2. Reagents and Primers for PCR Amplifications. The PCR reagents 5x GoTaq Flexi Buffer, $25 \mathrm{mM} \mathrm{MgCl}_{2}, 10 \mathrm{mM}$ dNTP, and Taq polymerase were obtained from Promega (Madison, WI, USA) and all of the PCR primers used were obtained from Invitrogen (Carlsbad, CA, USA). Forward (sense) primers were fluorescently labeled with FAM (absorption $494 \mathrm{~nm}$, emission $522 \mathrm{~nm}$ ) and reverse (antisense) primers were fluorescently labeled with HEX (absorption $535 \mathrm{~nm}$, emission $553 \mathrm{~nm}$ ) to enhance the ease of identification between the forward and reverse single-strand peaks in the electropherograms. Once the primers were obtained, they were diluted to a stock concentration of $100 \mu \mathrm{M}$ and this solution was used to make a working solution of $20 \mu \mathrm{M}$ for the PCR reactions. After preparing the PCR mixture, it was placed in an Apollo ATC401 thermocycler (Ramsey, MN, USA). A fragment of either the $16 \mathrm{~S}$ or $18 \mathrm{~S}$ gene variable regions was amplified using the primer pairs shown in Table 2.

The appropriate fluorescently labeled primer pairs were used in a PCR reaction mixture $(20 \mu \mathrm{L})$ consisting of $14 \mathrm{ng}$ of DNA, 1X GoTaq Flexi Buffer, $0.2 \mathrm{mM}$ dNTP, $20 \mu \mathrm{M}$ primer (forward and reverse), $2.0 \mathrm{mM} \mathrm{MgCl}_{2}$, and $2.5 \mathrm{U}$ of GoTaq polymerase (Promega Corp., Madison, WI, USA). After gently pipetting to mix and spinning the mixture for $\sim 15$ seconds to remove bubbles, the PCR mixture was subjected to the following amplification cycles on an Apollo ATC401 thermocycler: $95^{\circ} \mathrm{C}$ for 2-5 minutes, 30-35 cycles each of $95^{\circ} \mathrm{C}$ for $30-45$ seconds, $5^{\circ} \mathrm{C}$ below the melting temperature of the primer with the lowest temperature for 30-45 seconds, and $72^{\circ} \mathrm{C}$ for $45-60$ seconds, followed by one cycle of final 


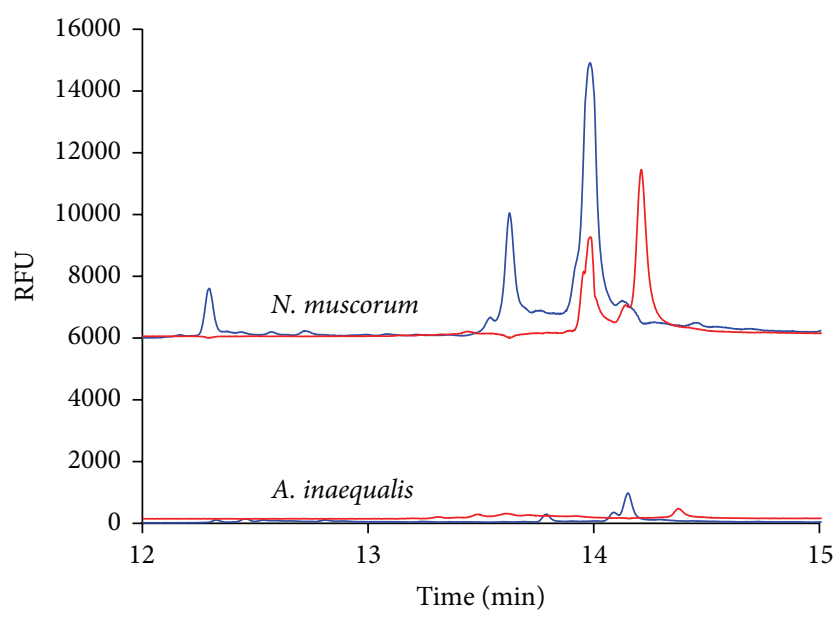

(a)

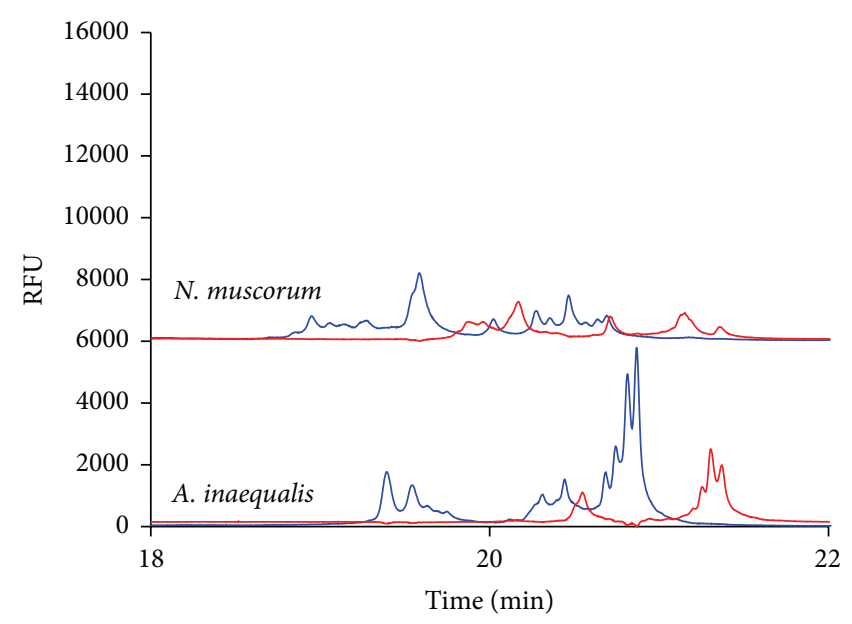

(b)

FIGURE 1: Detection of the (a) early and (b) later migrating peaks formed from the $16 \mathrm{~S}$ rDNA gene variable region 2 as detected by CE-SSCP for the cyanobacteria (prokaryotic) N. muscorum and A. inaequalis samples.

extension step at $72^{\circ} \mathrm{C}$ for 5-20 minutes, with temperature, time, and cycle ranges based on an optimization of the program and the melting temperatures of the different primer pairs.

\subsection{PCR Amplified DNA Samples Purification, Quantifica-} tion, and Storage. Amplified DNA fragments were purified using the QIAquick-Spin PCR Purification Kit (Qiagen Inc., Valencia, CA, USA) following the manufacturer's instructions. Quantification of purified DNA was determined with a Nanodrop 1000 spectrophotometer (Thermo Scientific, Wilmington, DE, USA) based on the absorbance of DNA at $260 \mathrm{~nm}$. The purified samples were used as a stock solution for preparing SSCP samples and were stored at $-20^{\circ} \mathrm{C}$.

2.4. CE-SSCP Sample Preparation. The fluorescently labeled purified DNA stock solutions were diluted to $1 \mathrm{ng} / \mu \mathrm{L}$ with $10 \mathrm{mM}$ Tris-HCL $(\mathrm{pH} 8.0)$ to obtain a $15 \mathrm{nM}$ solution for SSCP. Ten $\mu \mathrm{L}$ of the diluted, purified DNA was loaded per well into 4 wells of a 96-well plate followed by a denaturing step at $95^{\circ} \mathrm{C}$ for 3 minutes on the ATC 401 thermocycler. The samples were immediately snap-cooled on ice for 3 minutes before loading onto the ABI 3130 Genetic Analyzer (Applied Biosystems, Foster City, CA, USA) which has a four-capillary array. The capillaries were $36 \mathrm{~cm}$ in length with an inner diameter of $50 \mu \mathrm{m}$. The capillaries were loaded with the $3.5 \%$ PDMA polymer for 2 to $3 \mathrm{~min}$ and preelectrophoresis was performed for $3 \mathrm{~min}$ at $417 \mathrm{~V} / \mathrm{cm}$. The DNA samples were injected at $333 \mathrm{~V} / \mathrm{cm}$ for 15 seconds and separated at $417 \mathrm{~V} / \mathrm{cm}$ $(15 \mathrm{kV})$ with an associated current of $37.5 \mathrm{~mA}$ at $25^{\circ} \mathrm{C}$. The ABI 3130 utilizes LIF detection with a $488 \mathrm{~nm}$ Showa Laser (25 mW, $7.5 \mathrm{amps}$ ) and has an electrokinetic injection method.

2.5. Preparation of Polymer. Polydimethylacrylamide (PDMA) polymer was synthesized using the method of Albarghouthi et al. except with a decrease in the nitrogen bubbling time (from 16 hours to 4 hours) [23]. After completion of the reaction, the polymer was purified by dialysis in deionized water using Spectra-Por cellulose ester dialysis membranes (Spectrum, Gardena, CA, USA), having a molecular mass cutoff of $1000 \mathrm{Da}$. The deionized water was changed 10 times in 5 to 10 days. After dialysis was complete, the polymer was frozen at $-80^{\circ} \mathrm{C}$ for 48 hours and then recovered by lyophilization (Labconco, Kansas City, KS, USA). Dry polymers were dissolved in the running buffer which was $1 \mathrm{x}$ TBE buffer $+10 \%$ glycerol ( $89 \mathrm{mM}$ Tris-base, $89 \mathrm{mM}$ boric acid, $2 \mathrm{mM}$ EDTA, and $10 \%$ glycerol) to obtain polymer concentrations of $3.5 \%(\mathrm{w} / \mathrm{v})$. The diluted polymer was stored at room temperature.

\section{Results}

3.1. Pure Culture "Fingerprints". For each type of algae (prokaryotic or eukaryotic), two different variable regions were analyzed by CE-SSCP. For the prokaryotic algae (cyanobacteria), variable regions 2 and 3 of the 16S rDNA gene were analyzed. Figure 1 shows the electropherograms of the SSCP products of variable region 2 of the 16S rDNA gene of two prokaryotic algae species Anabaena inaequalis (A. inaequalis) and Nostoc muscorum (N. muscorum). Since multiple peaks were detected over a significant range of migrations times, the electropherograms were split into two different graphs. It should be noted while migration times can vary slightly from run to run due to the injection of fresh polymer, for a set of runs, the RSD value was $0.39 \%$.

The peak patterns in Figure 1(a) show a marked difference between the two species. There are three very strong forward (blue) and two reverse (red) peaks between the 12- to 15minute migration time for $N$. muscorum, while $A$. inaequalis had only one very small forward and reverse peak during this same migration time. Figure $1(b)$ is a continuation of this graph and shows the later migrating single-stranded DNA conformers. Again there were significant differences 


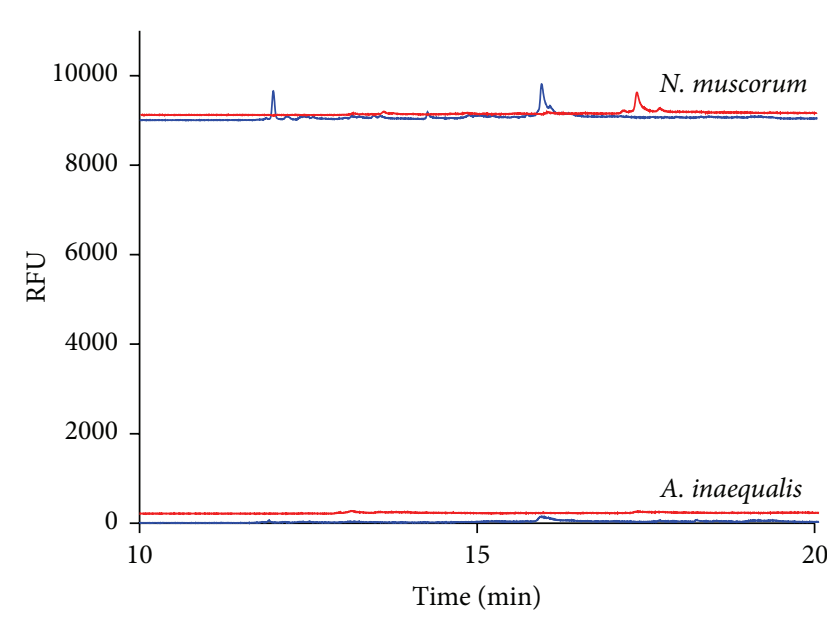

(a)

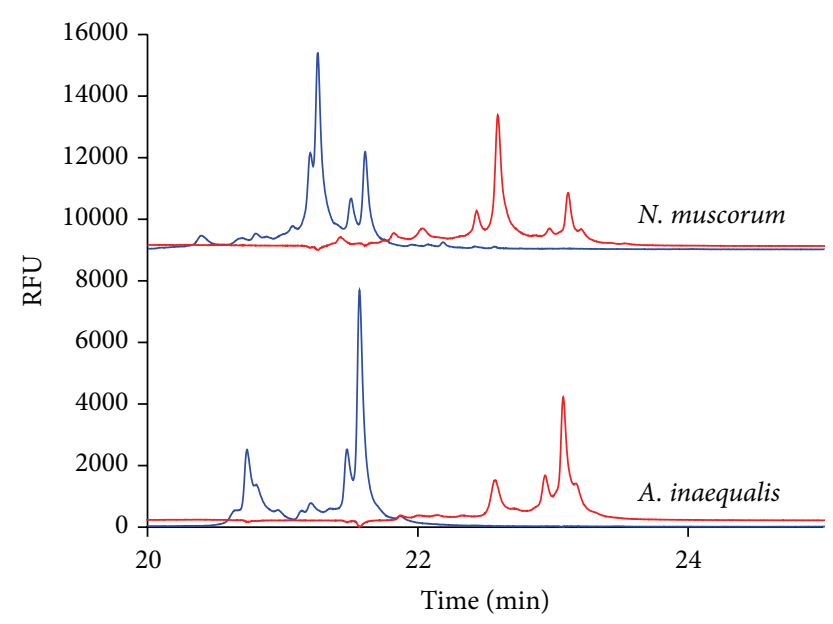

(b)

FIGURE 2: Detection of the (a) early and (b) later migrating peaks formed from the $16 \mathrm{~S}$ rDNA gene variable region 3 as detected by CE-SSCP for the cyanobacteria (prokaryotic) N. muscorum and A. inaequalis samples. Forward or sense strands are represented in blue while reverse or antisense strands are represented in red.

between the peak patterns. N. muscorum generated ten small forward peaks and five small reverse peaks, while $A$. inaequalis had eight larger forward peaks and three reverse peaks. Both N. muscorum and A. inaequalis demonstrated multiple peaks which were often in clusters. In an ideal CESSCP electropherogram, there would be a single peak for each species. Multiple peaks that are very close together, as seen in Figure 1(b) especially, could indicate that the "pure" culture sample was actually multiple subspecies with slight variations in the sequence. Alternative, multiple peaks have been previously detected for pure DNA samples where the sequences allowed for multiple highly favorable conformations to be formed during the snap-cooling process [24]. The same amount of primer was used in each reaction, so the amplification efficiencies of the different algae DNA templates may have resulted in different electropherogram peak intensities. There is also the possibility of multiple and/or different copies of the same $16 \mathrm{~S}$ rDNA gene in some species. This could explain the differences in intensities and/or the presence of multiple peaks in the algae samples. The presence of multiple peaks is not a result of the simultaneous amplification using two fluorescently labeled primers. The electropherograms produced from amplifications with one labelled and one nonlabelled primer were identical to those produced from each strand in the dual labeled samples.

The CE-SSCP electropherograms for the second 16S rDNA gene variable region examined (variable region 3) are shown in Figure 2. Figure 2(a) shows the early migrating peaks (between 10 to $20 \mathrm{~min}$ ); there are two very small forward peaks and one reverse peak for N. muscorum while A. inaequalis has no discernable peaks. In Figure 2(b), $N$. muscorum has four larger forward peaks and five reverse peaks. The reverse strands of both $N$. muscorum and $A$. inaequalis are at approximately the same migration time, but $N$. muscorum has a small peak at the 22-minute mark. A. inaequalis has four forward peaks in the 20- to 24-minute migration time period.
These two peaks at 21.5 minutes look very similar to the same peaks for N. muscorum. However, the first set of peaks for A. inaequalis at the 20.8-minute time has a difference in the migration time giving a slightly different pattern between the two species. The electropherograms or "fingerprint" patterns produced by these two cyanobacteria are extremely stable and the differences between them are repeated in all of the duplicated CE-SSCP runs $(n \geq 4)$. Therefore, these "fingerprint" differences clearly demonstrate how the electropherogram pattern could be used to differentiate between these two species. However, while the distinct pattern of peaks was very repeatable, the multiple peaks can create difficulties involved in interpreting these patterns as they can mask separate peaks and make the pattern difficult to read. Two different regions of each gene were examined to ensure verification of separate patterns for each species. For these two prokaryotic algae, the $16 \mathrm{~S}$ rDNA gene variable region 2 provides the clearest differences in CE-SSCP patterns between the two species, although both variable regions could be used to differentiate them.

After comparing two species of cyanobacteria using two variable regions of the $16 \mathrm{~S}$ rDNA gene, we looked at several species of eukaryotic algae. The eukaryotic algae are of a higher cell complexity and have an 18S rDNA gene in their nucleus. Therefore the DNA sample is from the $18 \mathrm{~S}$ rDNA gene variable regions 7 and 9, respectively. Figure 3 provides a comparison of six species shown in the same graph to highlight the differences between both similar and dissimilar species of algae and how CE-SSCP can be used to distinguish between them. Four of these eukaryotic species belong to the phylum Chlorophyta and two belong to the class Chlorophyceae which is one of the classes of green algae [6], while one is in the phylum Charophyta (a conjugating algae), and one is in the phylum Ochrophyta (a brown algae) [25].

As with the cyanobacterium, there are distinct differences in the patterns between the algal species. In Figure 3(a), the brown algae Ectocarpus sp. shows multiple small peaks 


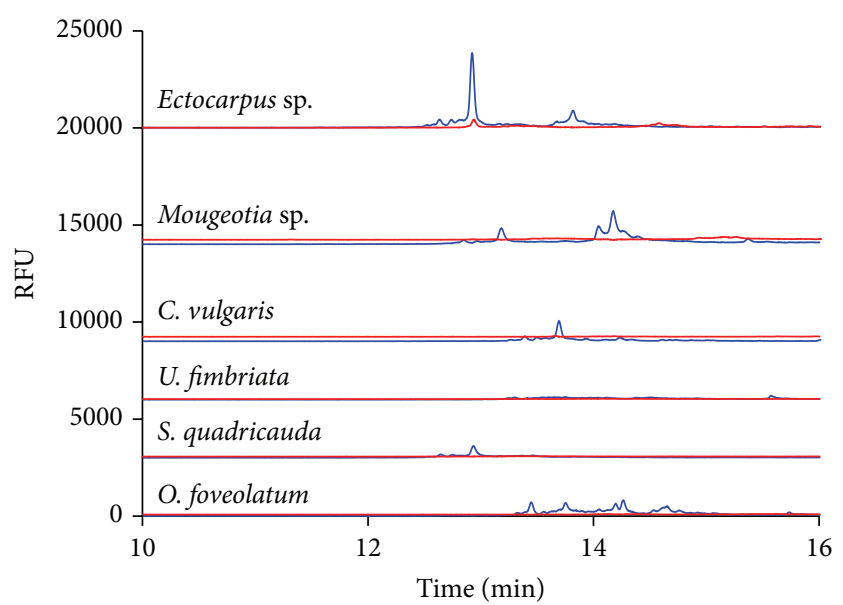

(a)

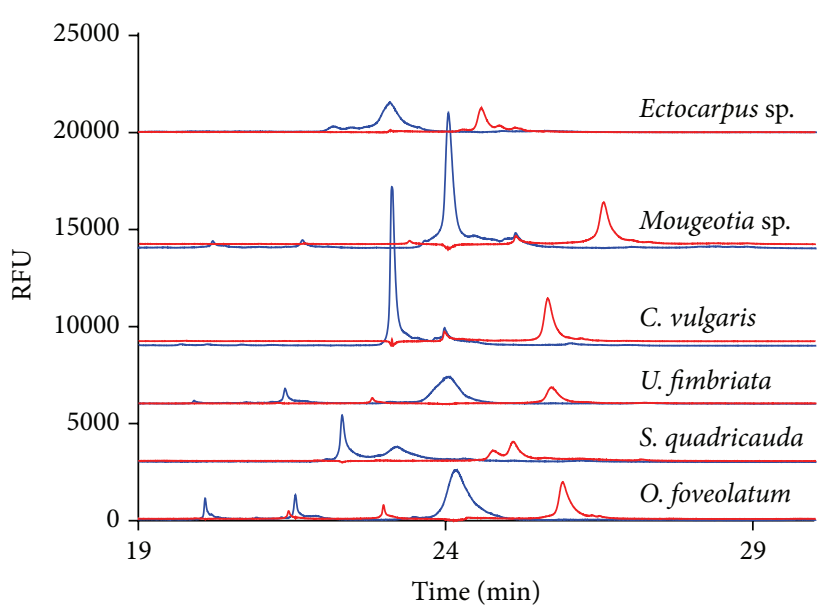

(b)

FIGURE 3: Detection of the (a) early and (b) later migrating peaks formed from the $18 \mathrm{~S}$ rDNA variable region 7 as detected by CE-SSCP for green and brown algae. Forward or sense strands are represented in blue while reverse or antisense strands are represented in red.

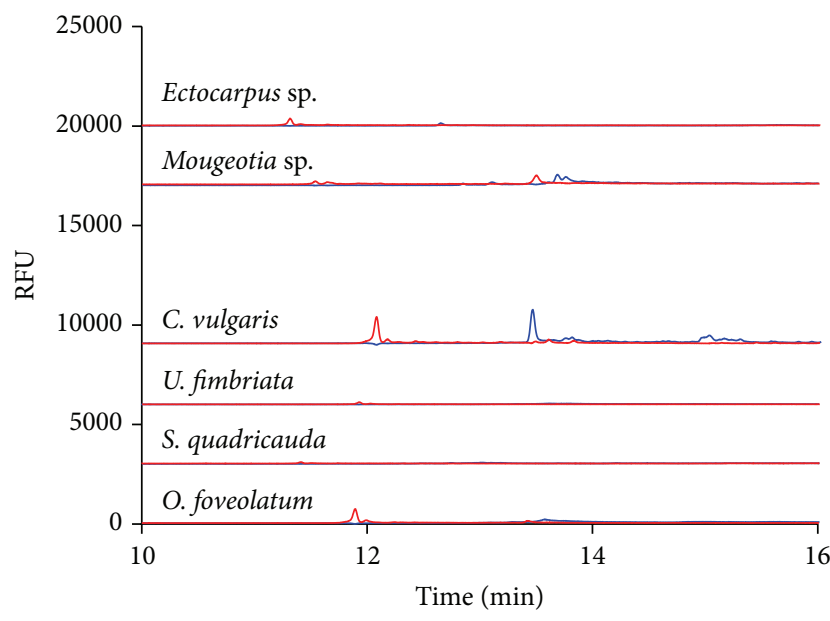

(a)

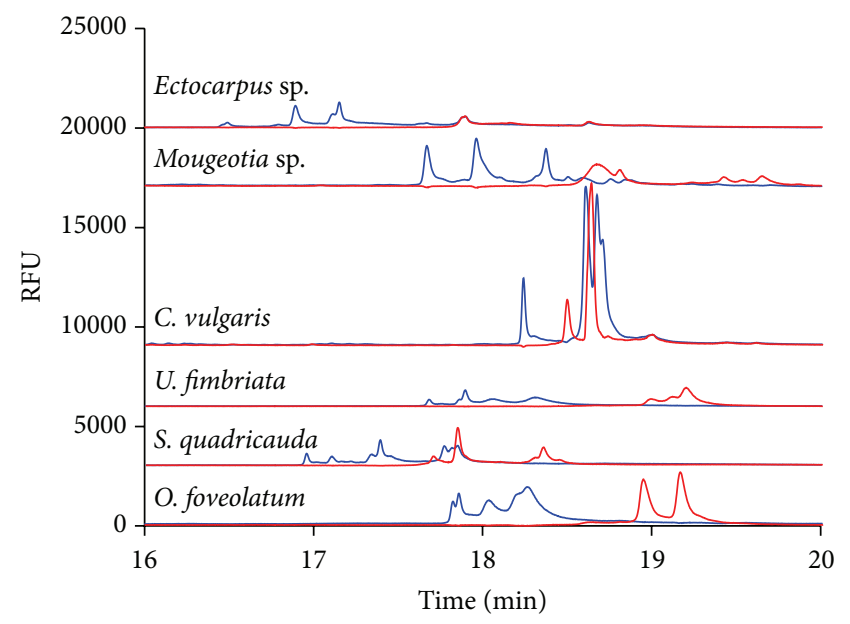

(b)

FIGURE 4: Detection of the (a) early and (b) later migrating peaks formed from the $18 \mathrm{~S}$ rDNA variable region 9 as detected by CE-SSCP for the green and brown algae. Forward or sense strands are represented in blue while reverse or antisense strands are represented in red.

immediately followed by a single large peak at 13 minutes and multiple smaller peaks at 13.8 minutes. Mougeotia sp. has a small peak at 12.5 minutes followed by multiple larger peaks at 13.5 minutes, while Chlorella vulgaris (C. vulgaris) has a single small forward peak just before the 14-minute migration time, and Ulothrix fimbriata (U. fimbriata) has only a very small peak at 15.5-minute migration time. Scenedesmus quadricauda (S. quadricauda) has a small peak at 13 minutes and Oedogonium foveolatum (O. foveolatum) has multiple very small peaks from 13 to 15 minutes. Interestingly, the early migrating peaks are almost all for the forward strand of DNA.

In Figure 3(b) both Mougeotia sp. and C. vulgaris have a large forward strand peak very close to the 23-minute migration point, as does the brown algae Ectocarpus sp., while $U$. fimbriata has two smaller peaks at 21.5 and 24 minutes. $S$. quadricauda has two slightly larger forward peaks at 22 and
23 minutes, and $O$. foveolatum has two small forward peaks at 20 and 21.5 and a larger forward peak at 24 minutes. In the reverse DNA strand, O. foveolatum, U. fimbriata, C. vulgaris, and Mougeotia sp. all have a similar peak around 26 minutes, while $S$. quadricauda and Ectocarpus sp. have several smaller peaks around 25 minutes.

The forward and reverse strands of the DNA give a pattern that is repeatable but in some cases may not differentiate enough between very similar species. This is the reasoning behind using at least two different variable regions; if one region cannot differentiate decisively between the patterns a second region may be examined. In Figure 4, a different variable region (variable region 9) was explored for these same six algae. In Figure 4(a), Ectocarpus sp. has small reverse peaks at 11.5 minutes, Mougeotia sp. has a reverse peak at 13.5 minutes, and C. vulgaris and O. foveolatum have small 
reverse peaks around 12 minutes. C. vulgaris also has a significant forward peak around 13.5 minutes. There are no early migrating peaks for S. quadricauda or U. fimbriata. In Figure 4(b), Ectocarpus sp. has a small reverse peak at 18 minutes, while Mougeotia sp. has multiple, larger peaks at 18.5 and 19.5 minutes. C. vulgaris has a large reverse peak at 18.5 minutes, while $U$. fimbriata has small multiple peaks at just past 19 minutes. S. quadricauda has three small reverse peaks just before 18 minutes, and $O$. foveolatum has two larger peaks at 19 minutes. The forward strands of DNA also have quite different patterns. Ectocarpus sp. has three small forward peaks at 17 minutes, while Mougeotia sp. has three forward peaks at 17.8-, 18-, and 18.3-minute migration time. C. vulgaris has a larger peak at 18.5 minutes followed closely by a triple peak pattern (somewhat obscured by the reverse peak overlaid on top of them) at just before the 19 minutes. U. fimbriata has small multiple peaks just after the 18-minute mark and S. quadricauda has four small forward peaks through 17 to 18 , while $O$. foveolatum has a larger triple peak around 18 minutes.

The advantages of CE-SSCP are the rapid analysis and clear differences in peak patterns. These changes in pattern could be used to detect changes in an algal population over time, effectively giving a "snapshot" of changes in either a closed or open system. The pattern is highly repeatable; in other words, the nucleotide sequence determines the shape and therefore the mobility of the conformers and this shape does in fact give a specific pattern that can be considered a "fingerprint." Using the two different variable regions, we were able to show differences in the peak patterns of both prokaryotes and eukaryotes. Even very similar algal species had distinct, repeatable patterns. While the pattern or fingerprint is unique to the algal DNA sequence, there is not necessarily just one peak for each sequence. There are several sequences that give multiple peaks patterns. These peaks could indicate that the "pure" cultures are not genetically pure or more likely represent different conformers from the same sequence.

\section{Conclusions}

CE-SSCP is a relatively fast, easy, and inexpensive method for determining changes in a small section of DNA such as a variable region of the $16 \mathrm{~S}$ or $18 \mathrm{~S}$ rDNA gene of the small subunit of the ribosome. In this work, CE-SSCP demonstrated the ability to differentiate between two different blue-green algae, five different green algae, and one brown algal species. The "fingerprint" patterns obtained through CE-SSCP of two variable regions from the $16 \mathrm{~S}$ rDNA gene and two variable regions from the $18 \mathrm{~S} \mathrm{rDNA}$ gene were highly repeatable and unique to each species. This technique shows significant potential for being differentiating algae and could be used to monitor an algal system over time.

\section{Conflict of Interests}

The authors declare that there is no conflict of interests regarding the publication of this paper.

\section{References}

[1] E. W. Becker, Microalgae: Biotechnology and Microbiology, Cambridge University Press, 1993.

[2] B. C. Christner, B. H. Kvitko II, and J. N. Reeve, "Molecular identification of bacteria and eukarya inhabiting an Antarctic cryoconite hole," Extremophiles, vol. 7, no. 3, pp. 177-183, 2003.

[3] H. Hillebrand, C.-D. Dürselen, D. Kirschtel, U. Pollingher, and T. Zohary, "Biovolume calculation for pelagic and benthic microalgae," Journal of Phycology, vol. 35, no. 2, pp. 403-424, 1999.

[4] J. W. G. Lund, C. Kipling, and E. D. Le Cren, "The inverted microscope method of estimating algal numbers and the statistical basis of estimations by counting," Hydrobiologia, vol. 11, no. 2, pp. 143-170, 1958.

[5] R. Rowan and D. Powers, "Molecular genetic identification of symbiotic dinoflagellates (zooxanthellae)," Marine Ecology Progress Series, vol. 71, pp. 65-73, 1991.

[6] R. E. Lee, Phycology, Cambridge University Press, Cambridge, UK, 2008.

[7] I. A. Abbott, Marine Algae of California, Stanford University Press, Redwood City, Calif, USA, 1992.

[8] M. N. Widjojoatmodjo, A. C. Fluit, and J. Verhoef, "Rapid identification of bacteria by PCR-single-strand conformation polymorphism," Journal of Clinical Microbiology, vol. 32, no. 12, pp. 3002-3007, 1994.

[9] R. Ghozzi, P. Morand, A. Ferroni et al., "Capillary electrophoresis-single-strand conformation polymorphism analysis for rapid identification of Pseudomonas aeruginosa and other gram-negative nonfermenting bacilli recovered from patients with cystic fibrosis," Journal of Clinical Microbiology, vol. 37, no. 10, pp. 3374-3379, 1999.

[10] F. Schwieger and C. C. Tebbe, "A new approach to utilize PCRsingle-strand-conformation polymorphism for $16 \mathrm{~S}$ rRNA genebased microbial community analysis," Applied and Environmental Microbiology, vol. 64, no. 12, pp. 4870-4876, 1998.

[11] W. Martin, T. Rujan, E. Richly et al., "Evolutionary analysis of Arabidopsis, cyanobacterial, and chloroplast genomes reveals plastid phylogeny and thousands of cyanobacterial genes in the nucleus," Proceedings of the National Academy of Sciences of the United States of America, vol. 99, pp. 12246-12251, 2002.

[12] C. R. Woese, "Bacterial evolution," Microbiological Reviews, vol. 51, no. 2, pp. 221-271, 1987.

[13] F. T. Bakker, J. L. Olsen, W. T. Stam, and C. van den Hoek, "The cladophora complex (Chlorophyta): new views based on 185 rRNA gene sequences," Molecular Phylogenetics and Evolution, vol. 3, no. 4, pp. 365-382, 1994.

[14] F. Duthoit, L. Tessier, and M.-C. Montel, "Diversity, dynamics and activity of bacterial populations in "Registered Designation of Origin" Salers cheese by single-strand conformation polymorphism analysis of $16 \mathrm{~S}$ rRNA genes," Journal of Applied Microbiology, vol. 98, no. 5, pp. 1198-1208, 2005.

[15] S. Chakravorty, D. Helb, M. Burday, N. Connell, and D. Alland, "A detailed analysis of $16 \mathrm{~S}$ ribosomal RNA gene segments for the diagnosis of pathogenic bacteria," Journal of Microbiological Methods, vol. 69, no. 2, pp. 330-339, 2007.

[16] K. Doi, H. Doi, E. Noiri, A. Nakao, T. Fujita, and K. Tokunaga, "High-throughput single nucleotide polymorphism typing by fluorescent single-strand conformation polymorphism analysis with capillary electrophoresis," Electrophoresis, vol. 25, no. 6, pp. 833-838, 2004. 
[17] M. Orita, H. Iwahana, H. Kanazawa, K. Hayashi, and T. Sekiya, "Detection of polymorphisms of human DNA by gel electrophoresis as single-strand conformation polymorphisms," Proceedings of the National Academy of Sciences of the United States of America, vol. 86, no. 8, pp. 2766-2770, 1989.

[18] H. Tian, A. Jaquins-Gerstl, N. Munro, M. Trucco, L. C. Brody, and J. P. Landers, "Single-strand conformation polymorphism analysis by capillary and microchip electrophoresis: a fast, simple method for detection of common mutations in BRCA1 and BRCA2," Genomics, vol. 63, no. 1, pp. 25-34, 2000.

[19] S. King, B. R. McCord, and R. G. Riefler, "Capillary electrophoresis single-strand conformation polymorphism analysis for monitoring soil bacteria," Journal of Microbiological Methods, vol. 60, no. 1, pp. 83-92, 2005.

[20] C. Delbès, L. Ali-Mandjee, and M.-C. Montel, "Monitoring bacterial communities in raw milk and cheese by culturedependent and -independent 16S rRNA gene-based analyses," Applied and Environmental Microbiology, vol. 73, no. 6, pp. 1882-1891, 2007.

[21] C. Y. Turenne, E. Witwicki, D. J. Hoban, J. A. Karlowsky, and A. M. Kabani, "Rapid identification of bacteria from positive blood cultures by fluorescence-based PCR-single-strand conformation polymorphism analysis of the $16 \mathrm{~S}$ rRNA gene," Journal of Clinical Microbiology, vol. 38, no. 2, pp. 513-520, 2000.

[22] A. Herrera-Sepúlveda, N. Y. Hernandez-Saavedra, L. K. Medlin, and N. West, "Capillary electrophoresis finger print technique (CE-SSCP): an alternative tool for the monitoring activities of HAB species in Baja California Sur Costal," Environmental Science and Pollution Research, vol. 20, no. 10, pp. 6863-6871, 2013.

[23] M. N. Albarghouthi, B. A. Buchholz, E. A. S. Doherty, F. M. Bogdan, H. Zhou, and A. E. Barron, "Impact of polymer hydrophobicity on the properties and performance of DNA sequencing matrices for capillary electrophoresis," Electrophoresis, vol. 22, no. 4, pp. 737-747, 2001.

[24] S. Krothapalli, M. K. May, and C. N. Hestekin, "Capillary electrophoresis-single strand conformation polymorphism for the detection of multiple mutations leading to tuberculosis drug resistance," Journal of Microbiological Methods, vol. 91, no. 1, pp. 147-154, 2012.

[25] M. D. Guiry and G. M. Guiry, AlgaeBase, World-Wide Electronic Publication, National University of Ireland, Galway, Ireland, 2013, http://www.algaebase.org. 

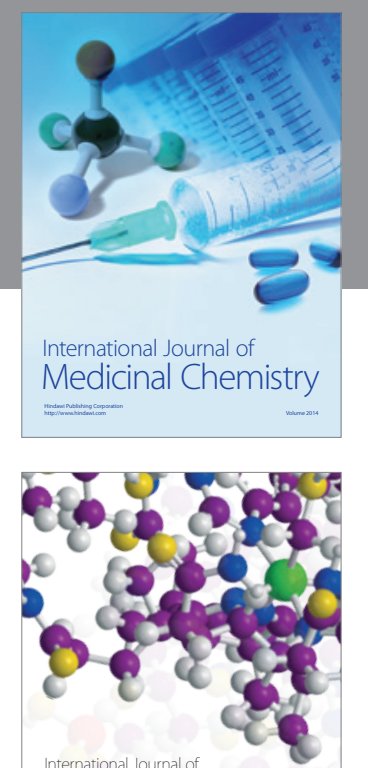

\section{Carbohydrate} Chemistry

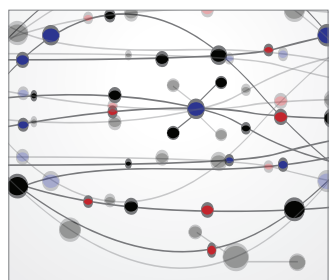

The Scientific World Journal
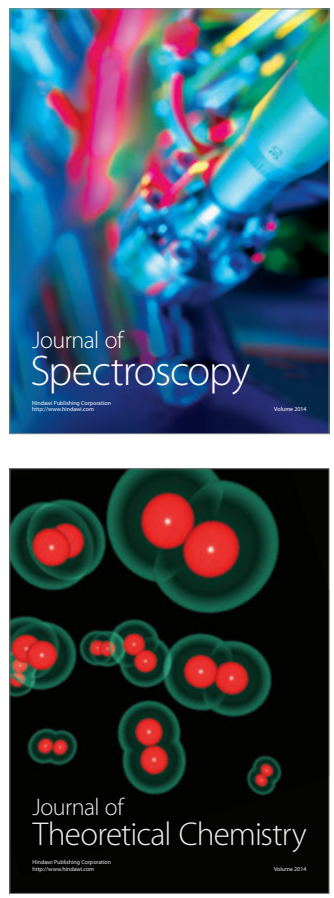
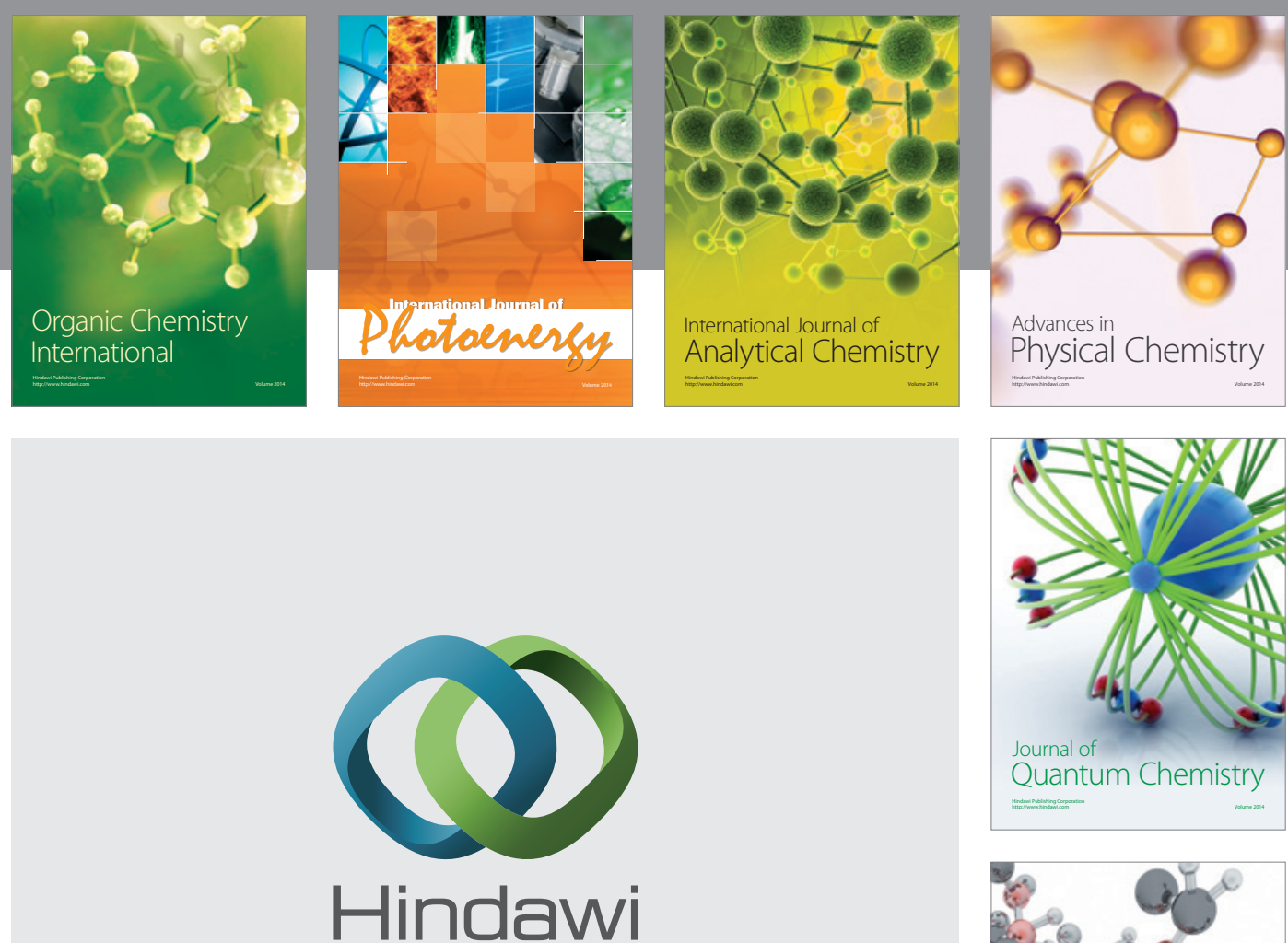

Submit your manuscripts at

http://www.hindawi.com

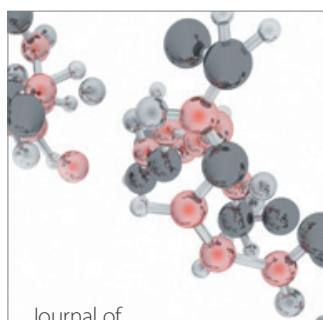

Analytical Methods

in Chemistry

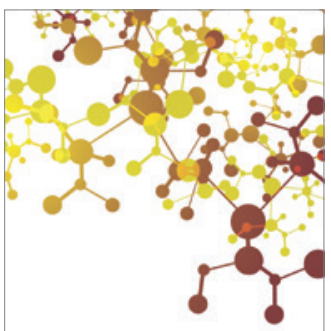

Journal of

Applied Chemistry

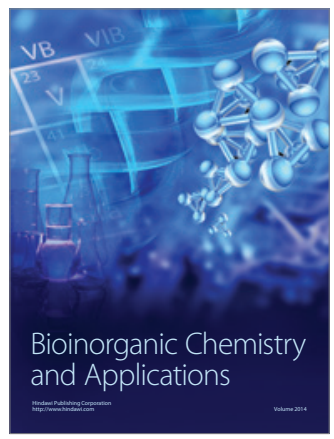

Inorganic Chemistry
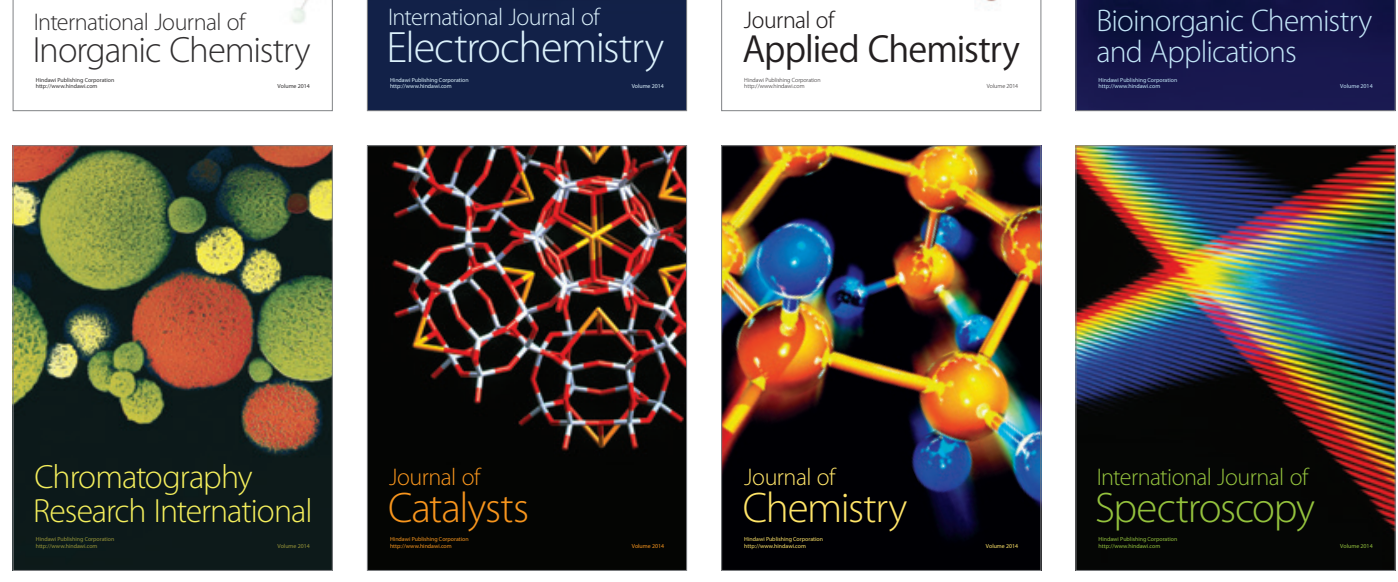